\title{
INOVASI DALAM PEMBELAJARAN SAINS MASA DEPAN MELALUI STEM (SCIENCE, TECHNOLOGI, ENGINEERING, AND MATHEMATIC) EDUCATION DI SMA MUHAMMADIYAH 3 JEMBER
}

\author{
${ }^{1)}$ Alvi Maulidia, ${ }^{2)}$ Albertus Djoko Lesmono, ${ }^{3)}$ Lailatul Nuraini \\ Program Studi Pendidikan Fisika FKIP Universitas Jember \\ Email: alvimaulidia@gmail.com
}

\begin{abstract}
This article discusses how to find out the level of student creativity in science learning, using the PBL (Problem Based Learning) learning model through the STEM approach (Science, Technology, Engineering, and Mathematics). The goal is to use these learning students who have different thought patterns and levels of creativity can process their thoughts with different outputs on the cognitive domain of students in learning physics in the material elasticity and hooke law in class XI Mipa 3 students at Muhammadiyah 3 High School Jember The data obtained in the form of worksheets (Student Worksheets) and the final product. This type of research uses true experimental research. The instruments needed in this research are test sheets. The results of this study are that using the STEM approach can provide innovative thinking for high school students' creativity in mastering physics learning.
\end{abstract}

Keywords: STEM Education, PBL model, thinking creativity.

\section{PENDAHULUAN}

Riset merupakan sarana yang penting untuk meningkatkan mutu pembelajaran. Komponen riset terdiri dari. Komponen riset terdiri dari latar belakang, prosedur, pelaksanaan, hasil, riset dan pembahasan serta publiksi hasil riset. Seluruh komponen tersebut memberikan makna penting yang dapat dilihat cara memformulasi dan menyelesaikan permasalahan serta kemampuan peneliti dalam mengkomunikasikan manfaat hasil penelitian tersebut (Widodo, 2016). Riset terbaru yang sedang ada saat ini salah satunya yaitu tentang STEM.

Saat ini STEM sudah dikenal di berbagai negara, baik negara maju maupun negara berkembang, pendidikan STEM dapat menjadi sebuah jalan keluar bagi masalah kualitas SDM dan daya saing masing-masing negara. Oleh sebab itu, dalam pendidikan STEM menjadi terobosan baru yang semakin mendominasi wacana dalam konferensi dan publikasi ilmiah internasional dalam bidang dunia pendidikan. Kesadaran akan pentingnya pendidikan STEM telah mulai muncul di kalangan pakar pendidikan di Indonesia, sehingga banyak kelompok studi di perguruan tinggi melakukan penelitian dan pengembangan pendidikan STEM.

Istilah STEM pertama kali yang digunakan oleh NSF (National Science Fondation) pada tahun 1990an sebagai singkatan dari science, technology, engineering and mathematics. Awalnya bukan berasal 
dari kata STEM melainkan kata SMET namun memiliki konotasi yang negative dengan kata smut. Kemudian diusualkan lagi dengan istilah kata METS namun di tentang kembali dan mendapatkan respon dari para anggota karena mengatakan bahwa kata METS adalah nama grup baseball Nasional di New York. Akhirnya muncullah sebuah akronim STEM dan istilah tersebut akhirnya disetujui oleh semua pihak anggota pada saat itu, karena banyak memiliki korelasi positif dengan bidang-bidang yang terkait (Sanders, Mark. 2009).

Definisi STEM berdasarkan kata masing masing diantaranya, Science: merupakan bagian dari ilmu pengetahuan yang mempelajari alam semesta, fakta-fakta, fenomena serta keteraturan yang ada di dalamnya. Technology: merupakan inovasi, perubahan, modifikasi dari lingkungan alam untuk memeberi kepuasan terhadap keinginan dan kebutuhan manusia. (standarad of technology literacy, ITEA 2000) Tujuan teknologi adalah membuat modifikasi pada dunia untuk memenuhi kebutuha manusia. (National Science Education Standard, NRC 1996) Dalam pemaknaan yang lebih luas, teknologi mempu meningkatkan kemampuan manusia untuk merubah dunia; memotong, membentuk, menyatukan material-material, meindahkan sesuatu dari satu tempat ke tempat lain, untuk menggapai sesuatu yang lebih hebat dengan menggunakan tangan, suara dan perasaan kita. (Benchnark for science literacy, AAAS, 1993), proses manusia memodifikasi alam untuk memenuhi kebutuhan dan keinginan mereka (Technically Speaking: Why All Americans Need to Know More About Technology, NAE/NRC,2012) Engineering: merupakan sebuah profesi dimana pengetahuan sains dan matematika diperoleh melalui studi, eksperimen, dan praktek yang diaplikasikan dengan mempertimbangkan pengembangan cara untuk merakit bahan-bahan dan kekutan alam untuk memenuhi kebutuhan manusia. (Accreditation Board for Engineering and Technology, 2008). Mathematics: merupakan cabang disiplin ilmu yang mempelajari berbagai pola atau hubungan (relasi). (AAAS, 1993).

Pendidikan STEM memiliki banyak memiliki banyak manfaat potensial bagi individu dan bangsa secara keseluruhan (Beatty, 2011). Bybee, 2013 mengatakan bahwa tujuan dari pendidikan STEM, agar peserta didik memiliki literasi sains dan teknologi tampaktampak dari membaca, menulis, mengamati, serta melakukan sains sehingga apabila mereka terjun didunia masyarakat, mereka akan mampu mengembangkan kompetensi yang telah dimilikinya untuk diterapkan dalam menghadapi permasalahan dalam kehidupan sehari-hari yang terkait dalama penerapan STEM.

Peningkatan kemampuan dan keterampilan bagi generasi muda calon tenaga kerja merupakan tanggung jawab dari dunia 
pendidikan (Supahar \& Istiyono, 2015). Merujuk pada tujuan utama pendidikan dalam STEM (sains, tekologi, teknik dan matematika) merupakan keterampilan penelitian untuk mendukung produksi pengetahuan ilmiah. Penelitian lebih lanjut untuk mengidentifikasi dampak diskrit dari praktek pendampingan khusus selama rekruitmen fakultas-mahasiswa mengenai pengembangan keterampilan penelitian siswa dan aspek pengembangan ilmiah lainnya akan meningkatkan dasar pembuktian praktik dalam pemdidikan (Feldon et al., 2016)

\section{METODE}

Penelitian ini dilaksanakan dengan metode penelitian diskriptif kualitatif dimana penilitian ini ingin mengetahui atau melihat adanya keadaan ataupun gejala dalam pelaksanaan penelitian, gejala yang terjadi ialah adanya hasil produk siswa dengan berbagai kreativitas yang setiap siswa berbeda-beda. Menurut Sugiyono (2005), penelitian deskriptif kualitatif merupakan penelitiam yang berusaha mendeskripsikan seluruh gejala atau keadaan yang ada, yaitu keadaan gejala dan fakta menurut apa adanya pada saat penelitian dilakukan. Subjek penelitian ini adalah siswa kelas XI Mipa 3 semester ganjil pada SMA Muhammadiyah 3 Jember tahun ajaran 2019/2020 waktu penelitian saat bulan Agustus 2019. Mata pelajaran fisika materi Elastisitas dan Hukum Hooke.
Kemudian dapat dilakukan pengelompokkan dalam kelas tersebut terbagi menjadi lima kelompok. Dengan penerapam model pembelajaran PBL (Problem Based Learning).

Prosedur penelitian ini meliputi beberapa tahapan, diantaranya tahap perencanaan, tahap pelaksanaan dan tahap evaluasi. Tahap perencanaan yaitu tahapan dimana siswa diberikan sebuah permasalahan dalam Lembar Kerja Siswa (LKS), dengan penerapan PBL STEM, siswa diberikan arahan materi umum tentang elastisitas dan hukum hooke, serta melihat literatur yang ada. Tahap pelaksanann dengan memberikan perlakuan kelompok siswa melakukan mengerjakan LKS dengan mendesai rancangan yang nantinya akan dibuat, menentukan pegas yang akan dipakai dan menghitung besarnya gaya yang terjadi pada pegas yang disusun dalam rancangan hingga menghasilkan produk dengan rancangan tiap kelompok yang berbeda-beda. Sedangkan tahap evaluasi dengan melakukan presentasi dan apresiasi pada tiaptiap kelompok serta menganilisis hasil rancangan yang dibuat pada tiap kelompok. Data dalam penelitian in berupa persoalan pada LKS dengan satu permasalahan yang ada di kehidupan sehari-hari dan tanggapan kelompok dengan mendesain pada lembaran tersebut.

HASIL DAN PEMBAHASAN 
Permasalahan yang diberikan kepada siswa di LKS (Lembar Kerja Siswa) sebelum melakukan kegiatan selanjutnya. Pada kelas XI Mipa 3 mendapatkan perlakuan berupa materi pembelajaran awal agar siswa dapat mengetahui literasi yang ada. Selanjutnya, setelah perlakuan awal tersebut, diberikan kesempatan siswa untuk memecahkan permasalahan dan merancang karya pada kelompoknya masing-masing.

Pembelajaran fisika pada materi elastisitas dan hukum hooke berbasis STEM ini menggunakan desain engineering processes dalam pembuatan miniature spring bed dan sofa, dari rancangan tersebut siswa harus berintegrasi dengan konsep matematika dalam menghitung besarnya gaya maksimal yang dapat diberikan. Hal tersebut dilakukan pada tiap kelompok agar dapat meningkatkan motivasi, tingkat belajar siswa, dan kreasi serta inovasi siswa dalam

Berdasarkan hasil penelitian, pembelajaran fisika berbasis STEM ini juga dapat memberikan pengaruh terhadap hasil belajar siswa untuk materi elastisitas dan hukum hooke menjadi lebih baik dibandingkan hasil belajar siswa pada materi lainnya. Hal tersebut dapat dilihat dari rata-rata nilai ulangan harian siswa. Maka dari itu masih diperlukan penelitian lebih lanjut mengenai pembelajaran fisika berbasis STEM terhadap berbagai kreativitas siswa tanpa harus melupakan pengaruhnya terhadap hasil belajar siswa.

Fakta dilapangan saat pembelajaran fisika berbasis STEM diimplementasikan masih terdapat banyak kendala, diantaranya kemampuan siswa dalam menganalisis permasalahan pada LKS (Lembar Kerja Siswa) masih harus diarahkan, butuh waktu yang lebih lama untuk melaksanakan pembelajaran dengan perlakuan ini dibandingkan dengan pembelajaran pada umumnya yang saat ini diterapkan dalam kurikulum 2013, pembuatan desain dan proyek miniature juga butuh waktu yang lebih banyak agar hasil produknya dikerjakan dengan baik. Namun pada saat proses pembelajaran berlangsung, guru dan siswa sudah terlibat dengan baik dalam berkomunikasi atau adanya sebuah timbal balik antara guru dan siswa. Adanya kelompok dalam pengerjaan pembelajaran STEM menjadikan murid dapat bekerja sama dalam satu tim yang dapat terintegrasi antara siswa satu dengan siswa lainnya dalam kelompok tersebut.

Secara keseluruhan, pembelajaran fisika berbasis STEM ini mampu meningkatkan kreativitas dan motivasi siswa. Meskipun pada SMA Muhammadiyah 3 Jember masih belum memahami pembelajaran dengan isitilah STEM, namun yang mereka rasakan pembelajaran dengan metode tersebut bisa membuat mereka berpikir secara aktif dan kritis. 
Proses pengambilan data yang dilakukan pada penelitian dirasa terlalu singkat sehingga siswa sendiri merasa masih kurang waktu untuk dapat menyelesaikan permasalahan dengan hasil yang baik. Oleh karena itu, durasi waktu pembelajaran yang lebih baik harus dilakukan pada penelitian-penelitian selanjutnya.

\section{KESIMPULAN}

Pembelajara fisika berbasis STEM pada materi elastisitas dan hukum hooke mampu meningkatkan kreativitas siswa menjadi lebih baik. Pembelajaran ini juga dapat meningkatkan pemahaman siswa mengenai materi tersebut serta meningkatnya hasil belajar pada siswa. Namun perlu dilakukan penelitian lebih lanjut terhadap kendala-kendala yang ada di lapang. Salah satu saran untuk penelitian selanjutnya yaitu dengan pengaturan dan manajemen waktu agar proses pembeajaran STEM dapat berjalan dengan baik dan sesuai dengan penelitian yang diinginkan, STEM juga dapat dilakukan di laboratorium fisika atau di lingkungan luar sekolah sebagaimana menurut Lilik Hendrajay 2015 mengatakan, Ilmu Pengetahuan Alam khususnya fisika seharusnya diajarkan juga secara kontekstual dengan alam sebagai sumbernya.

\section{DAFTAR PUSTAKA}

Accreditation Board for Engineering and Technology. (20072008). Engineering accreditation criteria.

Baltimore, MD: Author.

AAAS. (1993). Benchmarks for science literacy. New York, NY: Oxford University Press.

Beatty, A. 2011. Succesfull STEM Education a Workhop Summary.

Bybee, R. W. 2013. The Case for STEM Education: Challenges and Opportunity. Arlington, Virginia: National Science Teachers Association (NSTA) Press.

National Academy of Engineering (NAE). 2012. The grand challenges of engineering. www.engineeringchallenges. org

National Research Council. (2010, Draft under review). Framework for science education.Washington, DC: National Academy Press.

Sanders, Mark. 2009. STEM, STEM Education, STEMmania. The Technology Teacher. 2 (2009), 20-26.

Supahar, \& Istiyono, E. 2015. Pengembangan Asesmen.

Suwarma. R. Irma (2015), Research on Theory and Practice STEM Education Implementation in Japan and Indonesia using Multiple Intelligences Approach, 
Disertasi program doctor Shizuoka University.

Sugiyono. 2005. Metode Penelitian Administrasi. Bandung: Alfabeta.

Widodo, W., Setiawan, B., Astriani, D., Budiyanto, M., \& Rosdiana, L. 2016. Laporan Kegiatan Sanctioning Tahap 2: dalam Rangka Pengembangan Kurikulum Program Studi IPA, Fakultas Matematika dan Ilmu Pengetahuan Alam, Universitas Negeri Surabaya. (pp. 1-63). Surabaya: PIU IDB Unesa. 